\title{
Narrativas Visuales y Niñez: Procesos de creación de ilustradores brasileños en la literatura infantil
}

Hanna Araujo mailprahanna@gmail.com

Unicamp, Brasil

Reference

Araujo, Hanna; (2012) "Narrativas Visuales y Niñez: Procesos de creación de ilustradores brasileños en la literatura infantil", p. 173-178 . In: Barbosa, Helena; Quental, Joana [Eds]. Proceedings of the 2nd International Conference of Art, Illustration and Visual Culture in Infant and Primary Education. São Paulo: Blucher, 2015. ISSN 2318-695X, ISBN: 978-989-98185-0-7 DOI 10.5151/edupro-aivcipe-34

Esta comunicación intenta una aproximación al momento de la creación de ilustradores brasileños buscando comprender, las formas poética y creativa de narración visual. La investigación se basó en entrevistas a tres ilustradores brasileños que dirigen sus producciones, especialmente a los niños. Los artistas elegidos son Angela Lago, André Neves y Graça Lima, quienes tienen un sólido trabajo artístico y son renombrados en el mercado editorial brasileño recibiendo muchos premios internacionales. En sus recuerdos, los artistas expusieron los detalles de la creación de narrativas visuales para niños y sobre la intención de desarrollar la mirada del lector, buscando un refinado sentido estético. En sus declaraciones, muestran que la formación estética y educativa es intencional, construyendo sentidos junto al lector, conscientes de su responsabilidad social como artistas. Partimos del concepto de mediación semiótica desarrollado por Vygotsky. Tomamos como aporte teórico en las Artes Visuales las contribuciones de Ostrower y Gombrich. narrativas visuales; proceso de creación artística; ilustradores brasileños

Abstract

This paper aims to discuss the creative process of Brazilian illustrators in order to understand their poetic and creative production of their visual narratives. For the study we present, interviews were carried out with three Brazilian illustrators that have directed their production mainly toward child audiences. The selected participants were Angela Lago, André Neves and Graça Lima, all of whom have solid careers in the art field and are renowned in the Brazilian editorial market, having also received international awards. In their enunciations, the artists address their experience in creating visual narratives for children and their intentions in conduction the reader 's eye while enabling the development of their aesthetic response. Their discourse revealed that they are conscious that artists that produce for child audiences have a social responsibility. We based our work on the conception of semiotic mediation elaborated by Vygotsky. In visual arts, the theoretical framework we used came from contributions from Ostrower and Gombrich.

\section{Introducción}

Esta comunicación intenta una aproximación al momento de la creación de ilustradores brasileños, buscando comprender las formas poética y creativa de narración visual. Consiste en la conclusión de los estudios de Magíster en Artes realizado en la Universidad Estadual de Campinas- Brasil. Esta narrativa visual, a la que nos referimos, se caracteriza por un "libro de imágenes" (o Picture book) y el desarrollo de la narrativa que ocurre primordialmente a través de la composición imagética. Así, es un material accesible en muchos aspectos diferentes, que 
permite la lectura tanto a niños pequeños como también a adultos. La imagen en el libro es como un juego para el niño, que nombra y es nombrado, que se esconde y se revela, que crea significados con la literatura infantil y sus mediadores, sean sus padres, sus maestros u otros niños. Y, sobre todo, permite infinitas posibilidades de lectura.

La investigación se basó en entrevistas con tres ilustradores brasileños que dirigen sus producciones especialmente a los niños. Los artistas elegidos fueron Angela Lago, André Neves y Graça Lima, quienes tienen un sólido trabajo artístico y son renombrados en el mercado editorial brasileño recibiendo muchos premios internacionales. En sus recuerdos los artistas expusieron los detalles de la creación de narrativas visuales y sobre la intención de desarrollar la mirada del lector, buscando un refinado sentido estético.

Partimos del concepto de mediación semiótica desarrollado por Vygotsky, en la que los sujetos sociales se relacionan a través de signos. Tomamos como aporte teórico en las Artes Visuales las contribuciones de Fayga Ostrower y Gombrich. Los datos fueron reunidos a través de entrevistas semi-estructuradas, grabadas y transcritas. También estudiamos las secuencias de ilustraciones narrativas de obras seleccionadas de y por cada artista, con el fin de captar las diferencias y especificidades en cuanto a la narración escrita y pictórica. Existen muchos factores que emergieron en los discursos de los ilustradores en la construcción de significados, entre sus imágenes y los niños: la técnica utilizada, el diseño gráfico y la estructura narrativa son pruebas concretas, que llevan a la lectura de las imágenes y construyen significados con los lectores. En sus declaraciones muestran que intencionan la formación estética y educativa, construyendo sentidos junto al lector.

Los discursos de los artistas revelan que ellos tienen consciencia de su responsabilidad social como artistas que producen para niños. Esta responsabilidad significa más que entretenerlo, es seducir y atraer al niño que está iniciándose en el camino de la lectura y lo hace a través de su proceso creativo. Cuando el artista trabaja en el libro, busca inserir significados en la creación de imagen, que son detentoras de una poética y una estética propia, derivadas de su proceso creativo y unido a la imagen. El libro para niños permite que ellos imaginen la historia a partir de sus propias percepciones, guiadas a través de las marcas fijadas por el artista en su proceso de creación.

Buscamos estudiar, a través de las entrevistas con los artistas, el proceso de producción de constitución de la poética en las obras, buscando el significado emergente de los procesos de creación. Las entrevistas fueron de suma importancia para la investigación, una vez que nos basamos en las descripciones de cada artista acerca de la obra finalizada, esbozos y materiales del proceso de creación, siendo el significado que las personas traspasan a las cosas y a su vida, el foco de atención especial de los investigadores, en la tentativa de capturar la perspectiva de los participantes (LÜDKE; ANDRÉ, 1987). Buscábamos esbozos, bosquejos, frases escritas, cualquier registro material que nos enseñase los caminos de la investigación creativa, de las elecciones realizadas y de las numerosas posibilidades que los materiales sugirieron.

\section{Procesos de creación: la produción artística y su especificidad}

La creación de imágenes en secuencia narrativa exige del artista una preparación que transpone el dominio de la técnica, esta entendida como un conjunto de procesos de determinada arte. Para componer imágenes con valor estético, los artistas necesitan de una mezcla de habilidades inherentes al trabajo artístico, sumado a las intenciones educativas que permean esta modalidad de producción, cuando son pensadas para el público infantil y juvenil. Las imágenes pueden reforzar ideas estereotipadas y prejuiciadas, así como pueden ser libertarias, ampliando y reelaborando la tolerancia en frente al otro, al diferente. Componer una imagen que estará en un libro, no es puramente poner representaciones en la hoja que correspondan a sentidos de frases escritas. Cuando el artista trabaja en el libro, él busca atribuir sentidos a la imagen que construye, siendo estas, detentoras de una poética y de una estética propia, derivadas del proceso creativo y fijadas en la imagen.

Entendemos que el artista deja marcas de diversos tipos en el trabajo, sin ser necesariamente consciente de ello. Buscamos en las declaraciones de los artistas, acerca de los elementos básicos de construcción de sentido que fueron marcados intencionalmente por ellos en las 
$2^{\text {nd }}$ International Conference Art, Illustration and Visual Culture in Infant and Primary Education $2^{\circ}$ Congreso Internacional

Arte, Ilustración y Cultura Visual en Educación Infantil y Primaria
${ }^{\circ}$ Congresso Internacional

de Arte, Ilustração e Cultura Visual

na Educação Infantil e Primária

\subsection{Artistas: \\ experimentación, intuición y experiencia}

Figura 1. Angela Lago, Cena de Rua, 1994. Foto del autor, 2010. imágenes producidas, con la clara distinción que su composición puede conducir/direccionar la lectura de la imagen, guiando la atención del lector. Sin embargo, también, en las palabras de los artistas, los significados percibidos después de haber tenido contacto con las lecturas de otras personas, resignificaban su propia imagen. El material empírico utilizado en esta investigación, consistió en entrevistas semi-estructuradas con los artistas.

Para la realización de esta investigación tuvimos que escoger a los artistas. Encontramos en el mercado editorial brasileño muchos ilustradores que tienen un fuerte trabajo como artista. Encontramos muchos artistas creadores de libros muy buenos que contemplaban las características que juzgamos esenciales en un libro para niños, en cuanto a criterios estéticos, poéticos y pedagógicos. El siguiente paso consistió en la contemplación de las obras que habíamos elegido. En este punto, utilizamos como criterio, el deleite del objeto artístico. Posteriormente, establecimos un índice que certificase la calidad de la producción artística, a saber, el reconocimiento de sus pares a través de premios. Por lo tanto, hemos seleccionado tres artistas que han recibido algunos premios de Mejor llustración y / o Mejor Libro llustrado por FNLIJ (Fundación Nacional del Libro infantil y Juvenil- sección brasileña del IBBY ) y / o el "Premio Jabuti", de la Cámara Brasileña del Libro, en la categoría llustración para niños. Otro criterio para elegir a los artistas fue la producción de una variedad de libros y con variación en el repertorio técnico de ilustración. Los artistas seleccionados fueron los siguientes: André Neves, Angela Lago y Graça Lima.

Angela Lago tiene 30 años de experiencia en la producción de libros para niños. Consultada acerca de la presencia o ausencia de texto en sus libros, sobre las posibilidades que se presentan en sus procesos creativos, la artista explica que en cada proyecto enfrenta la cuestión acerca de la presencia del texto o no. Explicó que tiene más intimidad con la imagen, y que lo malo era que el texto es necesario en determinados momentos e inapropiados en otros. En su obra 'Cena de Rua' (Figura 1), Angela Lago, declaró que el texto que falta se debió a la inadecuación del tema, atribuyendo la ausencia de un texto narrativo al grado del tema:

¿lmagina escribir este libro con el texto? Sería intolerable la posibilidad de texto porque quedaría un texto muy demagógico. (...) Con la imagen, puedo hablar de desigualdad, con la palabra no sería capaz, creo que sería demagógico. El texto no se ajusta, y sería ridículo, sin fuerza, sin elocuencia, sin drama, o un drama sensiblero, un drama demagógico. (Lago, 2008)

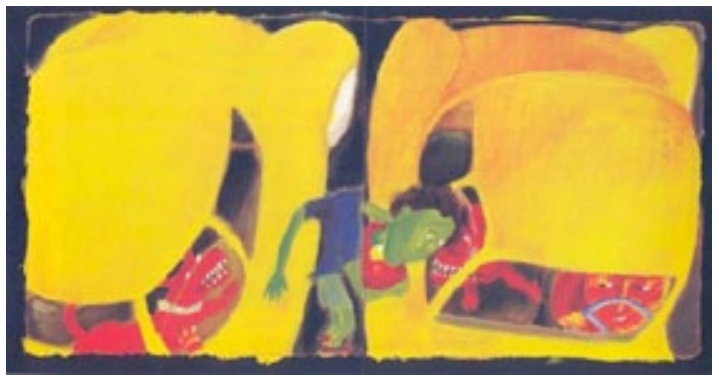

Creemos que el artista invierte en proyectos verdaderamente significativo, la colocación de los elementos que tenga sentido, también, para sus lectores. Su producción artística tiene motivos intencionales de existir, sus propósitos son claros. Su intención está marcada por la necesidad de anhelo de comunicación, de formación estética y educativa. Así, para Ostrower (1990),

A técnica representa um instrumento de trabalho, que o artista precisa conhecer- evidentementedominar com plena soberanía (aqui entenda-se bem: cada artista há de encontrar suas técnicas; não todas as técnicas do mundo, nenhum artista pretende ser um dicionário ambulante de técnicas). Mas nas obras de arte, as técnicas acabam se tornando invisíveis sendo absorbidas inteiramente pelas formas expressivas. (p.18) 
$2^{\text {nd }}$ International Conference Art, Illustration and Visual Culture in Infant and Primary Education
André Neves se posiciona como artista, al explicar los motivos por los cuales produce libros de imágenes:

Otra cosa que me hace crear un libro de imagen y sacar las palabras, no escribir, es el simple hecho de que soy un artista visual. La palabra viene de mi imagen y nunca fue al contrario. Entré en esta profesión como artista visual, como un artista visual y no verbal. Fue la imagen que me llevó a crear palabras. (Neves, 2008)

La técnica consiste en el metie del quehacer artístico, consistiendo en el conjunto de procesos derivados de una práctica. La experimentación de técnicas es la forma de explotar las posibilidades plásticas y expresivas. Las obras de los tres artistas contienen fuertes vestigios de la experimentación, de exploración e inquietación. En la búsqueda de reinventar las experimentaciones conducen el proceso de creación (y de significación) hacia caminos distintos, tales como un juego de ensayo y error, en el que las rutas de viaje se conocen y muchas otras están por conocer. Las producciones de los artistas muestran que dominan todos los procesos que incluyen la construcción de sus imágenes, como el diseño gráfico, el uso del color, etc., en las cuales, es evidente el dominio de la técnica en la composición de imagen.

Con el pasar de los años, el artista se da cuenta que la técnica artística puede ser aprendida por cualquier persona que vive en la cultura, expresando con ello algunas experiencias personales que han llegado a ser posible en un contexto cultural determinado.

Para Ostrower, la técnica es una herramienta de trabajo que el artista debe conocer y dominar con plena soberanía, "mas nas obras de arte, as técnicas acabam se tornando invisíveis sendo absorvidas inteiramente pelas formas expressivas". (1990:18).

Otro punto importante en el proceso de creación artística es la comprensión del libro como soporte, como sustrato de la imagen. La composición de los elementos que desencadenan una narración, requiere un conocimiento previo de las estructuras plásticas necesarias, como el dominio técnico del objeto artístico - libro-, necesariamente. Sin embargo, la complejidad de la estructura narrativa, teniendo en cuenta imágenes en secuencia narrativa, se compone de un complicado trabajo de artista, conocedor de la organización del espacio, de un refinado sentido estético, de un humor refinado, consciencia de sus fines educativos, etc.

Entre las distintas técnicas disponibles, los artistas las eligen de acuerdo a sus preferencias. Con respecto al uso del computador, por ejemplo, Angela Lago lo utiliza como herramienta de trabajo actual, para maravillarse con las infinitas posibilidades de construcción visual.

Nunca he tenido tanta oportunidad de tener mi propio pincel. Por supuesto, usted puede hacerlo con un cepillo, lo corta, pero la posibilidad es mayor, de experimentación en la computadora. Es el pincel de nuestro tiempo. Y el diseño es todo, es el texto del libro es la imagen y es el libro. Es un gran pincel. (LAGO, 2008)

A Graça Lima, por su vez, le gusta ejecutar sus imágenes en papel y tinta, rechazando El computador como herramienta de creación (Figura 2).

No puedo trabajar muy bien con el computador. Necesitaba saber, pero tengo una fascinación con el color, no tengo ningún prejuicio contra el computador no, es que no sé cómo usarlo. Creo que es genial, pero no sé si lo tengo que hacer, prefiero coger el papel, pasta. (LIMA, 2008)

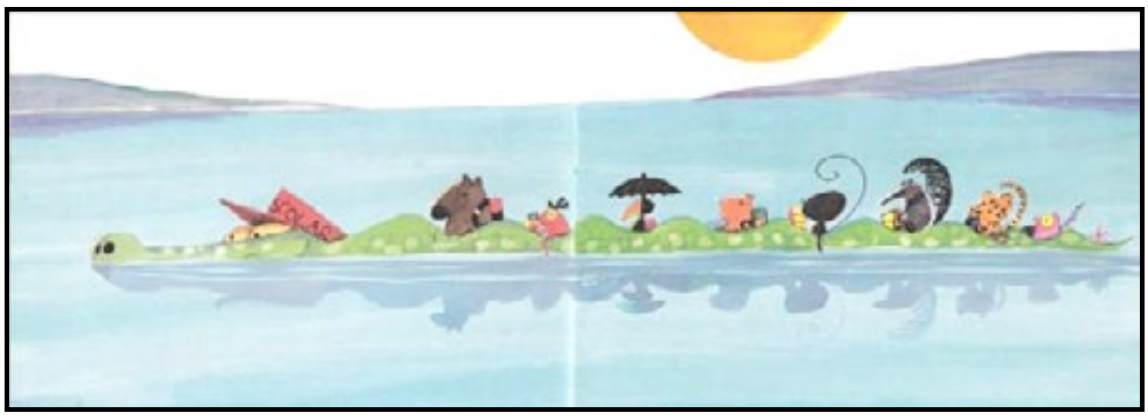


$2^{\text {nd }}$ International Conference Art, Illustration and Visual Culture in Infant and Primary Education
Figura 2. André Neves, Seca, 2000 Foto del autor, 2010.
En su práctica, André Neves prefiere explorar las posibilidades visuales de sus libros, cuyas páginas están enriquecidas con numerosos detalles de texturas y capas superpuestas. André admite que la ejecución de sus imágenes le ofrece satisfacción, y que el desarrollo de las texturas y detalles son la parte divertida de su trabajo:

Me gusta trabajar con los detalles. No me gusta poner un fondo cualquiera. Tengo placer de realizar. Me gusta descubrir otras posibilidades con la tinta. A veces se tarda en secar, a veces no funciona. Me gusta experimentar, usar todo lo que me viene a la mente. A veces no puedo repetir algunos de los resultados. Pero no me sorprendería tratar con otros resultados. Me gusta eso. Mi trabajo es muy experimental. (NEVES, 2008)

La obra de arte requiere del artista dos niveles de habilidad. El primero es la estructura mental de la obra, cuáles son sus concepciones, intenciones y expectativas con respecto al producto final. Además, la implementación física de la obra a veces se mueve en caminos que no corresponden a lo esperado. Estos niveles no son visibles por separado y se entrelazan a lo largo del período de creación. La técnica tiene un fuerte papel en la construcción de significado en la imagen. El uso de la técnica debe ser empleada a favor del proyecto de la imagen y se utiliza para ampliar las posibilidades narrativas. Las técnicas, materiales y colores sugieren significados de acuerdo con el modo de disposición de los elementos.

Cuando el editor aceptó hacer este libro (Figura 2) me dijo, vamos a hacer un libro muy lindo, vamos a poner un papel muy bonito. Le dije que no. No quiero un papel lindo. Quiero uno sin brillo y seco. Quería darle esta cosa demasiado gruesa al lector. Quería que la gente sintiera, que se diera cuenta de la simplicidad, del aspecto de dureza. Yo quería un acabado rústico. (Neves, 2008)

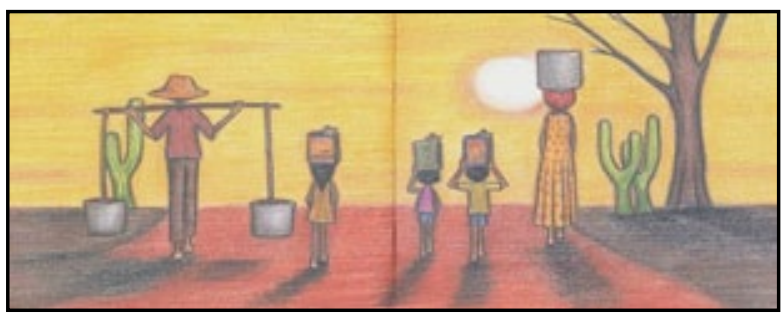

Para el artista lograr que la técnica resulte en la ampliación de los significados puestos en el libro, él necesita dominar el proceso de creación del libro, tales como los pliegues y cortes. El tipo de papel, así como el material utilizado, representó un importante factor para André Neves, que compromete la lectura de la imagen, aun que estos puntos no estén conscientemente entendidos por los lectores.

La intencionalidad, la necesidad de la expresión plástica, el mercado editorial, la idealización de los lectores, la insatisfacción artística, entre otros, fueron los puntos que recorrieron las palabras de André Neves, Angela Lago y Graça Lima. En esta investigación se observó que el artista deja marcas de diversa naturaleza, sin ser necesariamente consciente de eso. Se realizaron búsquedas en el discurso de los artistas para identificar los elementos de construcción de significados, que han sido inseridos intencionalmente por ellos en las imágenes, con la clara distinción que la composición puede conducir / dirigir la lectura de la imagen, mostrando el camino al lector. Sin embargo, también en las declaraciones de los artistas, se percibieron otros signos, ya que después de haber tenido contacto con las lecturas del exterior, resignificaron sus propias percepciones de la imagen que producían. Intentó ser una contribución a la comprensión del objeto libro para adultos mediadores, los modos de producción artística. En los artistas estudiados, las estructuras formales de la narrativa visual son fijadas en la experiencia. La relación con los demás, el contacto con la literatura, la música y muchos otros puntos, demostró la formación de sus referencias y la manera como fomentan sus producciones. 
2nd International Conference Art, Illustration and Visual Culture in Infant and Primary Education $2^{\circ}$ Congreso Internacional

Arte, llustración y Cultura Visual en Educación Infantil y Primaria $2^{\circ}$ Congresso Internacional

de Arte, llustração e Cultura Visual na Educação Infantil e Primária

\section{Referenciales bibliográficos}

Gombrich, E. (2003). Los usos de las imágenes. Ciudad de México: Fondo de cultura. Lago, A. (2008) Entrevista concedida ao autor. Belo Horizonte, MG- Brasil. Lima, G. (2008) Entrevista concedida ao autor. Rio de Janeiro, RJ- Brasil. Neves, A. (2008) Entrevista concedida ao autor. Porto Alegre, RS - Brasil. Ostrower, F. (1990). Acasos e Criação Artística. Rio de Janeiro: Campus. Vygotsky, L. (2009). A imaginação e a creación na infância. São Paulo: Martins Fontes. Lüdke, M; André, M.(1987) Pesquisas em Educação: abordagens qualitativas. São Paulo: EPU. 